\section{OP0151 AUTOANTIBODIES AGAINST DENSE-FINE- SPECKLED 70 (DFS70) DO NOT ENTIRELY EXCLUDE CONNECTIVE TISSUE DISEASES}

L. M. Mockenhaupt ${ }^{1}$, R. Dolscheid-Pommerich ${ }^{2}$, C. Behning ${ }^{3}$, B. StoffelWagner $^{2}$, P. Brossart ${ }^{1}$, V. Schäfer ${ }^{1} .{ }^{1}$ University Hospital Bonn, Clinic of Internal Medicine III, Department of Oncology, Hematology, Rheumatology and Clinical Immunology, Bonn, Germany; ${ }^{2}$ University Hospital Bonn, Institute of Clinical Chemistry and Clinical Pharmacology, Bonn, Germany; ${ }^{3}$ University Hospital Bonn, Institute of Medical Biometry, Informatics and Epidemiology, Bonn, Germany

Background: Antinuclear antibodies (ANA) are serological markers for the presence of rheumatic diseases [ $\left.{ }^{1}\right]$. In some patients, a pattern can be detected in ANA immunofluorescence that resembles an anti-dense-fine-speckled-70 antibody $\left.{ }^{2}\right]$. This is detected less frequently in patients with connective tissue diseases (CTD) and is therefore often used as an exclusion criteria for a CTD $\left[^{2}\right]$. To date, however, it is not clear how the presence of an anti-DSF70 autoantibody will reliably rule out CTDs.

Objectives: To examine the degree to which CTDs can be excluded from either a positive test and whether there are discrepancies between patients with CTDs and a negative anti-DSF70 test and those with CTDs and a positive anti-DSF70 test.

Methods: We analyzed data of 460 patients who were tested for the presence of the DSF70 antibody at the University Hospital Bonn, Germany. Patients were examined with regard to clinical symptoms and signs, type of disease, type of CTD, fulfillment of the classification criteria for the particular CTD, DSF70 antibodies, other autoantibodies and ANA titer. Gold standard for presence of a CTD was the diagnosis of the treating rheumatologist.

In addition to variations between patients with CTD and positive or negative DSF70 antibodies, specificity, sensitivity and positive predictive value were calculated for different ANA titers.

Results: Of the 460 patients, $79.8 \%$ were female and 182 were diagnosed with a CTD. 354 patients $(77.0 \%)$ were tested negative, $81(17.6 \%)$ positive and 25 $(5.4 \%)$ had a borderline anti-DSF70 autoantibody result.

We identified 21 patients with a positive test result in the presence of a CTD, which accounts for $25.9 \%$ of all anti-DSF70 autoantibody positive tested patients. We found no significant differences in DSF70-positive patients with CTD in regard to age, gender, symptoms, clinical signs and also disease-specific antibodies compared to patients with negative DSF70 status and present CTD.

Of the 21 DSF70-positive patients with CTD, $12(57.1 \%)$ were tested for the presence of disease-specific autoantibodies. Specific autoantibodies could be detected in all of the tested patients with systemic lupus erythematosus, systemic sclerosis, Sjögren's syndrome and mixed connective tissue disease.

DSF70 autoantibodies had a specificity of $86.8 \%$, a sensitivity of $26.9 \%$ and a positive predictive value of $68.2 \%$ at an ANA titer of $\geq 1: 160$, with respect to the absence of a connective tissue disease.

Table 1. Sensitivity, specificity and positive predictive value of antiDSF70 autoantibody in different ANA titers (borderline patients excluded)

$\begin{array}{lcc}\text { a) ANA-Titer } \geq 1: 80 & & \\ \text { N=362 } & \text { No present } \text { CTD } & \text { Present } \text { CTD } \\ \text { DSF70 positive } & 52 & 21 \\ \text { DFS70 negative } & 145 & 144 \\ \text { Positive predictive value }=71.2 \% & \text { Sensitivity: } 26.4 \% & \text { Specificity: } 87.3 \% \\ \text { b) ANA-Titer } \geq 1: 160 & & \\ \text { N=326 } & \text { No present } \text { CTD } & \text { Present } \text { CTD } \\ \text { DSF70 positive } & 45 & 21 \\ \text { DSF70 negative } & 122 & 138 \\ \text { Positive predictive value }=68.2 \% & \text { Sensitivity: } 26.9 \% & \text { Specificity: } 86.8 \% \\ \text { c) ANA-Titer } \geq 1: 640 & & \\ \text { N=167 } & \text { No present } \text { CTD } & \text { Present } \text { CTD } \\ \text { DSF70 positive } & 17 & 14 \\ \text { DSF70 negative } & 48 & 88 \\ & \text { Sensitivity: } 26.2 \% & \text { Specificity: } 86.3 \% \\ \end{array}$

Positive predictive value $=54.8 \%$

Conclusion: Autoantibodies to DSF70 often occur in CTD patients and are therefore not a valid exclusion criteria for a CTD. We observed no CTD in $68.2 \%$ of patients who were tested positive. Thus, in difficult situations, the DSF70 test may be helpful and the additional exclusion of other autoantibodies may render CTD even less probable.

\section{REFERENCES:}

[1] Mahler M, Fritzler MJ. Epitope specificity and significance in systemic autoimmune diseases: Epitope specificity. Ann N Y Acad Sci. 2010;1183(1):267-287.

[2] Mahler M, Hanly JG, Fritzler MJ. Importance of the dense fine speckled pattern on HEp-2 cells and anti-DFS70 antibodies for the diagnosis of systemic autoimmune diseases. Autoimmun Rev. 2012;11(9):642-645.
Disclosure of Interests: Louisa-Marie Mockenhaupt: None declared, Ramona Dolscheid-Pommerich: None declared, Charlotte Behning: None declared, Birgit Stoffel-Wagner: None declared, Peter Brossart: None declared, Valentin Schäfer Speakers bureau: AbbVie, Novartis, BMS, Chugai, Celgene, Medac, Sanofi, Lilly, Hexal, Pfizer, Janssen, Roche, Schire, Onkowissen, Royal College London, Consultant of: Novartis, Chugai, AbbVie, Celgene, Sanofi, Lilly, Hexal, Pfizer, Amgen, BMS, Roche, Gilead, Medac, Grant/research support from: Novartis, Hexal, Lilly, Roche, Celgene, Universität Bonn

DOI: 10.1136/annrheumdis-2021-eular.934

\section{OP0152 COMPARISON OF DIAGNOSTIC CRITERIA IN BEHÇET DISEASE AND SENSITIVITY IN DIAGNOSING SEVERE MANIFESTATIONS.}

C. Álvarez-Reguera ${ }^{1}$, A. Herrero-Morant ${ }^{1}$, L. Sanchez-Bilbao ${ }^{1}$, D. MartínezLópez $^{1}$, J. L. Martín-Varillas ${ }^{2}$, G. Suárez Amorín ${ }^{3}$, C. Mata-Arnaiz ${ }^{4}$, M. Á. González-Gay ${ }^{1}$, R. Blanco ${ }^{1} .{ }^{1}$ Hospital Universitario Marqués de Valdecilla, Rheumatology, Santander, Spain; ${ }^{2}$ Hospital de Sierrallana, Rheumatology, Sierrallana, Spain; ${ }^{3}$ Hospital Universitario Marqués de Valdecilla, Ophthalmology, Santander, Spain; ${ }^{4}$ Hospital de Laredo, Rheumatology, Laredo, Spain

Background: Behçet disease (BD) is characterized by painful recurrent oral aphthosis genital ulcers and skin lesions. Nevertheless, the major causes of morbidity result from ocular, vascular and neurological involvement. Diagnosis of BD is usually performed according to the International Study Group (ISG) (Lance 1990; 335:1078-80). Recently, criteria proposed by the International Team for the Revision of the International Criteria for BD (ITR-ICBD) have demonstrated a higher sensitivity (J Eur Acad Dermatology Venereol 2014;28:338-47).

Table 1. Main clinical features according to different diagnostic criteria. Patients characteristics, data are in $\mathbf{n}(\%)$

\begin{tabular}{lccc}
\hline & $\begin{array}{c}\text { Expert rheumatolo- } \\
\text { gists (N=120) }\end{array}$ & $\begin{array}{c}\text { ISG criteria } \\
\mathbf{( N = 5 9 )}\end{array}$ & $\begin{array}{c}\text { ICBD criteria } \\
\mathbf{( N = 9 6 )}\end{array}$ \\
\hline Age, mean years / (SD) & $38(13.8)$ & $35.6(13)$ & $37(13)$ \\
Gender, men/women, N (\%) & $62 / 58(52.1 / 47.9)$ & $29 / 30(49.1 / 50.8)$ & $48 / 48(50 / 50)$ \\
Oral aphthosis, N (\%) & $113(94.2)$ & $59(100)$ & $94(97.9)$ \\
Genital aphthosis, N (\%) & $71(78.5)$ & $46(78)$ & $71(74)$ \\
Skin manifestations N (\%) & $76(63.3)$ & $52(88.1)$ & $64(71.6)$ \\
Ocular lesions, N (\%) & $54(45)$ & $31(52.5)$ & $50(52.1)$ \\
Joint manifestations, N (\%) & $78(65)$ & $38(64.4)$ & $62(64.6)$ \\
Neurological manifestations, N (\%) & $23(19.2)$ & $9(15.2)$ & $20(21.1)$ \\
Vascular manifestations, N (\%) & $14(11.6)$ & $7(11.9)$ & $14(14.6)$ \\
Gastrointestinal features, N (\%) & $8(6.6)$ & $3(5.1)$ & $5(5.3)$ \\
\hline
\end{tabular}

Objectives: To assess a) the concordance and differences between ISG and ICDB criteria b) sensitivity in diagnosing severe manifestations (ocular, vascular and neurological).

Methods: The study included 120 patients diagnosed with definitive or possible BD by expert rheumatologists. They were diagnosed at a well-defined population in Northern Spain between January 1980 and December 2019. The ISG and ICBD diagnostic criteria for BD were applied to all patients and compared among them. Results: 120 patients (62 men/ 58 women) were studied. Mean age at diagnosis was $37.6 \pm 13.8$ years. $59(49.2 \%)$ patients fulfilled ISG criteria and $96(80 \%)$ ICBD criteria. Concordance between both criteria was moderate (Kappa 0.41). ICBD criteria diagnosed more patients with neurological $\left(\chi^{2}=49.1, p<0.01\right)$, vascular $\left(\chi^{2}=56.7, p<0.01\right)$ and ocular manifestations $\left(\chi^{2}=84.4 p<0.01\right)$ (Figure).

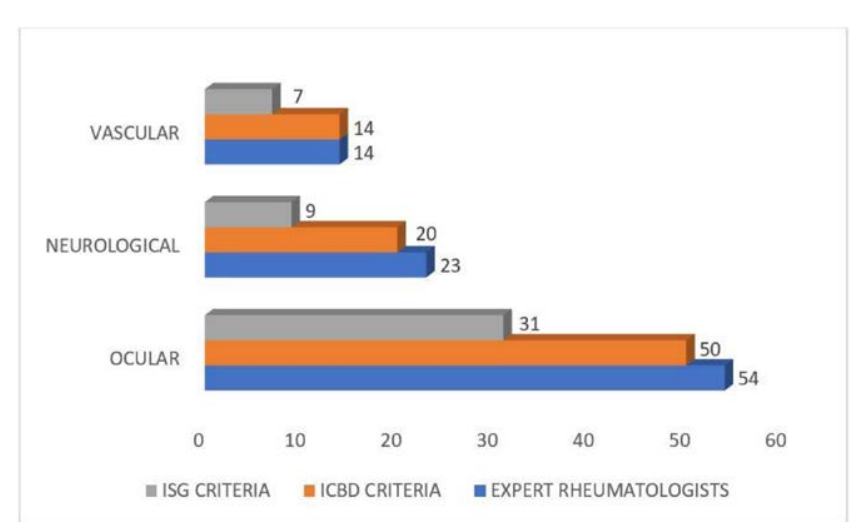

Figure 1. Number of patients with vascular, neurological or ocular manifestations diagnosed with BD by different criteria. Abbreviations: ITRC-ICBD: International Team for the Revision of the International Criteria for BD; ISG: International Study Group for Behçet Disease. 